\title{
Visual Tracking of Traffic Signals to Aid the Color- Blind Using Image Processing
}

\author{
Ravi Shankar ${ }^{1}$, Krishna Peri ${ }^{2}$ \\ ${ }^{1}$ Department of Management and Computer Science, Dr. L.B. College, Resapuvanipalem, Visakhapatnam, India \\ ${ }^{2}$ Department of Information Technology, GITAM University, Rushikonda, Visakhapatnam, India
}

\begin{abstract}
In the present day scenario, technology has evolved in such a way that it is helping humanity to overcome their disabilities. One such application of technology assisting the disabled is our proposed system where a visual system is used in aiding the colourblind. This application is used in domestic transportation wherein the visually challenged are guided by the system by notifying them about the status of traffic signals.
\end{abstract}

Keywords: color-blindness, image processing, visual system, medical aid

\section{Introduction}

Colour blindness restricts the affected drivers in deducing the status of the traffic signal. There is an appreciable number of accidents caused due to this inability. As of now, no team or individual has put forward credible ideas to tackle this problem. Our study aims at overcoming this obstacle. We aim to facilitate the affected in deducing the status of the signal.

\section{Color-Blindness}

Colour blindness is a condition wherein the eye cannot distinguish certain colours. Colour vision deficiencies can be classified as acquired or inherited. The types are:

- Acquired- due to disease or chemical intervention

- Inherited- monochromacy, dichromacy, and anomalous trichromacy.

The most commonly occurring conditions are dichromacy, $\mathrm{n}$ and anomalous trichromacy.

In dichromacy, the common types are:

- Protanopia- complete absence of red retinalphotoreceptors. Protans have difficulties distinguishing between blue and green colors and also between red and green colors.

- Deuteranopia- Green photoreceptors are absent. It affects hue discrimination in the same way as protanopia, but without the dimming effect.

In trichromacy, the common type is Deuteranomaly- shift in the green retinal receptors, is by far the most common type of color vision deficiency, mildly affecting red-green hue discrimination

\section{Proposed System}

- Using image processing techniques, we isolate the colours of the signal. Implementing a visual sensor aimed at the signals, we identify only the specific bands of colours.

- By means of audio or visual (written) cues, we notify the driver.

\section{Working}

\subsection{Overview}

We use a visual sensor to identify the color frequencies of the traffic signals. Generally, the diameter of the circular signal is 12 inches. Here, we are assuming the sensor to be ideally placed at a distance of 300 meters.

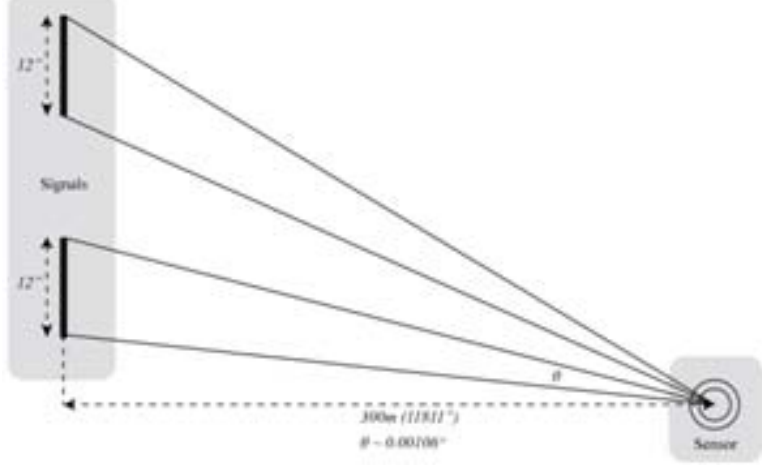

Figure 1: Simple representation of system

\subsection{Use of CdS Photocell}

A common CdS photocell has the same response as the human eye. Because colours absorb and reflect certain wavelengths, we can use different wavelengths of light and take readings from a sensor that has nearly same response as that of humans and thereby speculate at what colour the sensor is being exposed to.

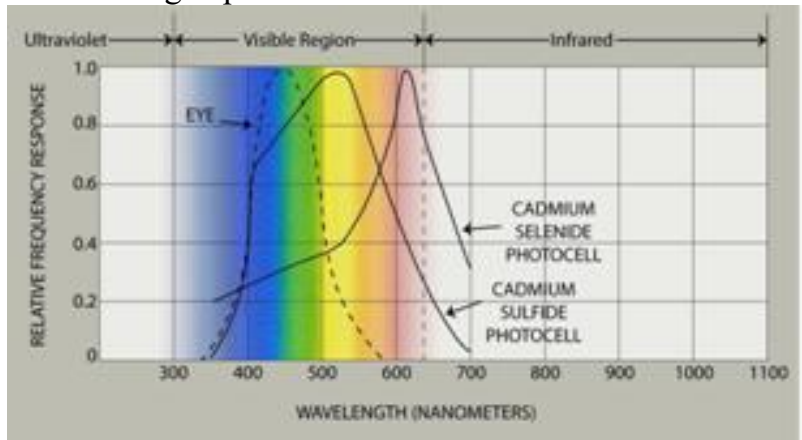

Figure 2: Characteristics curves of $\mathrm{CdS}$ and $\mathrm{CdSe}$ Photosensitive devices compared with the spectral response curve of the human eye 


\section{International Journal of Science and Research (IJSR) \\ ISSN (Online): 2319-7064}

Index Copernicus Value (2013): 6.14 | Impact Factor (2015): 6.391

\subsection{Basic Circuit}

The information from the sensor is fed into the Arduino and then into the microprocessor, where the logic is applied as to tell the sensor what color to recognize. A block diagram of the visual system is given below:

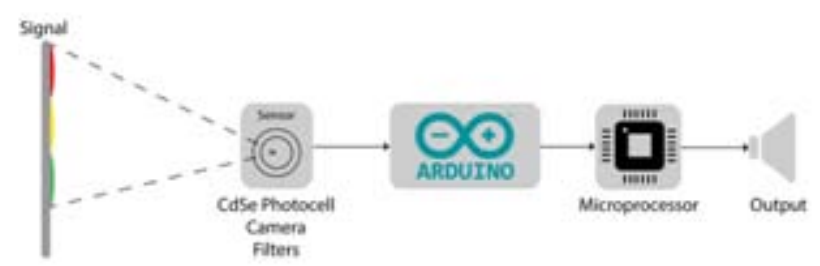

Figure 3: Block diagram of the basic visual system

The CdSe/CdS Photocell senses the oncoming traffic lights and recognizes the wavelengths of the colors. This information is fed into the Arduino where this information is digitized. The microprocessor takes the digital data and produces respective response at the final output.

\subsection{Calculations}

Resolving the signals at a distance is important. The minimum angle can be calculated using the following formula

$$
\theta=1.22 \frac{\lambda}{D}
$$

Wavelength (for LED signals) for red is $657 \mathrm{~nm}$ and for green it is $400 \mathrm{~nm}$.

Assuming the maximum distance to be $300 \mathrm{~m}$, and the diameter of the signal is 12 inches, a 2 megapixel camera meets the above requirements.

\section{Conclusion and Future Scope}

This idea can be further developed in such a way that it can overcome the following shortcomings:

- Different signal standards in different regions

- Environmental factors

- Increase in the length of sensitivity

- Higher resolving power of the sensor

Some of the updates which can be done on this proposed system are:

- Can be developed into an app

- Can be integrated with the car's navigation system

\section{References}

[1] "Types of Color Deficiencies". Konan Medical. Retrieved 2016-03-21.

[2] "Traffic Light Signals and Red Light Cameras". Geocities.com. Retrieved 2016-03-21.

[3] Pearce, Joshua M. 2012. "Building Research Equipment with Free, Open-Source Hardware". Science 337 (6100): 1303-1304. (open access)
[4] Using an RGB LED to Detect Colours [Online]. Available: http://www.instructables.com/id/Using-anRGB-LED-to-Detect-Colours/ [Accessed: March 25, 2016]

[5] PGM5506 Datasheet, Token Passive Components. Retrieved 2016-03-25.

\section{Author Profile}

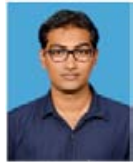

Ravi Shankar received his Bachelors in Physics from Sri Sathya Sai Institute of Higher Learning, Bangalore, India in 2010. He is pursuing his Masters in Computer Application in Dr. L.B. College, Visakhapatnam, India. He has written a paper on the use of computers in the field of Physics and its applications (Use of $\mathrm{C}++$ to determine risk of a nuclear establishment, under review).

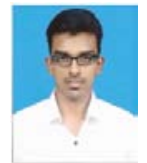

Krishna Peri is pursuing his Bachelors Degree in Information Technology in Gandhi Institute of Technology And Management, Visakhapatnam, India. $\mathrm{He}$ is currently working on the development of the project, "Secured Hash Password Authentication" as a part of his undergraduate curriculum. 